\title{
Responsible research and innovation (RRI) as a driving force for change in corporate communication: New forms of governance and participatory structures
}

\author{
Noelia García-Castillo; Tamara Bueno-Doral; Liisa-Irene Hänninen
}

Nota: Este artículo se puede leer en español en:

http://www.elprofesionaldelainformacion.com/contenidos/2020/may/garcia-bueno-hanninen_es.pdf

How to cite this article:

García-Castillo, Noelia; Bueno-Doral, Tamara; Hänninen, Liisa-Irene (2020). "Responsible research and innovation (RRI) as a driving force for change in corporate communication: New forms of governance and participatory structures". El profesional de la información, v. 29, n. 3, e290313.

https://doi.org/10.3145/epi.2020.may.13

Manuscript received on 8 June 2019 Accepted on 16 December 2019

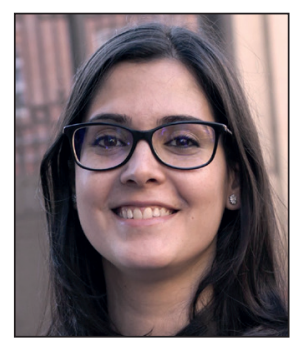

Noelia García-Castillo $\bowtie$ https://orcid.org/0000-0001-5875-0195

Universidad Complutense de Madrid Facultad de Ciencias de la Información Universidad Pontificia Comillas Facultad de Ciencias Humanas y Sociales Spain

ngarc02@ucm.es

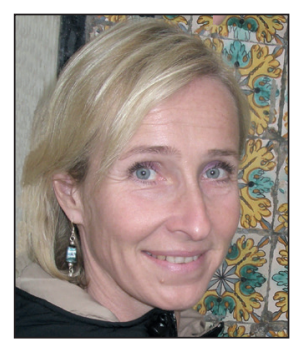

\author{
Liisa-Irene Hänninen \\ https://orcid.org/0000-0002-8567-4201 \\ Universidad Complutense de Madrid \\ Facultad de Ciencias de la Información \\ Avenida Complutense, 3 \\ 28040 Madrid, Spain \\ liisaire@ucm.es
}

\section{Abstract}

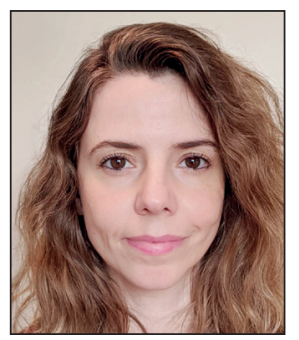

Tamara Bueno-Doral https://orcid.org/0000-0002-2954-1519

Universidad Complutense de Madrid Facultad de Ciencias de la Información Avenida Complutense, 3 28040 Madrid, Spain trbueno@pdi.ucm.es

Nowadays, the emerging discipline of Responsible Research and Innovation (RRI) has great acceptance among the scientific community in general. Nevertheless, its presence in social sciences has not reached the development obtained in other disciplines. Studies describing RRI application to areas such as business, and more specifically, corporate communication, are scarce. The objective of this study is to show the possible application of the principles of the emerging RRI discipline to business and corporate communication, as well as the main barriers and benefits that could arise. For this, we provide a documentary review of the existing literature and an analysis of fifteen semi-structured interviews with Spanish experts in RRI. Likewise, the article addresses the relationship between RRI and Corporate Social Responsibility (CSR). As a main conclusion, we observe that RRI has the potential to become the driving force for new forms of

\section{Acknowledgements \& financing}

We gratefully acknowledge the interest and efforts of the persons and institutions that have participated in this investigation, financed by the European Union through the Horizon 2020 program for the project 'Fostering a Transition towards Responsible Research and Innovation Systems (FoTRRIS)' (grant agreement 665906) and 'Reshaping Attention and Inclusion Strategies for Distinctively vulnerable people among the forcibly displaced (RAISD)' (grant agreement 822688). 
governance and communication, but requires changes in corporate philosophy and performance, as it is a bottom-up participatory movement, promoted by the objective of a sustainable society for future generations. In addition, this study represents a contribution to the current discussion regarding the application of the principles and processes of RRI beyond the academic field.

\section{Keywords}

Responsible Research and Innovation; RRI; Corporate Social Responsibility; CSR; Corporate communication; Organizational communication; Innovation; Stakeholders; Governance; Citizen participation.

\section{Introduction}

We currently find ourselves in a social and political scenario that, from a historical perspective, is new, and that each institution should view as a competitive opportunity (García-Marzá, 2018). As a result, it is essential to recover and empower persons and their institutions so that all may assume their ethical responsibilities. There are currently structures and persons capable of mobilisation, but this must be done democratically, respecting freedom and equality when taking decisions.

As Castells (2008) said over a decade ago, "in our society, power means the power to communicate", a communication that is transmitted through spaces in which both citizens, as prosumers, (Giraldo-Dávila; Maya-Franco, 2016) and businesses, governments and political institutions participate. All of these stakeholders and inter-relationships must be considered when studying the transformation of relationships of power and the practices of governance. This is because

"societies evolve and change, de-constructing their institutions under the pressure of new relationships of power and constructing new institutions, in which contradictory interests and values are combined" (Castells, 2008).

As we shall see shortly, these struggles for power will also affect the application of Responsible Research and Innovation (RRI) within business activities, taking us beyond Corporate Social Responsibility (CSR).

In the face of this social requirement of power for stakeholders (interested parties), RRI proposes aligning the development of research and innovation in organisations with society's real expectations. Therefore, we propose that RRI is a valid method for corporate communications. This substantial change would come about through the structural application of its four dimensions: anticipation, reflexivity, inclusiveness and responsiveness (Stilgoe; Owen; Macnaghten, 2013).

\section{Theoretical framework}

Von-Schomberg's definition of RRI by is the most commonly cited:

"A transparent, interactive process by which societal actors and innovators become mutually responsive to each other with a view to the (ethical) acceptability, sustainability and societal desirability of the innovation process and its marketable products (in order to allow a proper embedding of scientific and technological advances in our society)" (Von-Schomberg, 2013).

The Rome Declaration on responsible research and innovation defines RRI as

"the on-going process of aligning research and innovation to the values, needs and expectations of society" (European Union, 2014).

Meanwhile, the R\&D\&i Framework Program of the European Union's Horizon 2020 program incorporates RRI as a transversal aspect that foments institutional change via the participation of the parties implicated (stakeholders).

RRI is a multidisciplinary terminology, transversal and broad, still in a conceptualisation and negotiation stage, in the fields of both science and politics. Although there is a growing body worldwide of academic publications, its applications are still in the experimental phase. In Spain, the applications of RRI in the field of social sciences, and especially communications, are as yet scarce, and we can find few bibliographic references.

One of the main principles of RRI is to move attention from the results of innovation towards the entire process; only thus can we achieve a proactive innovation, via mechanisms that integrate responsibility from the very start of the process (Ribeiro; Smith; Millar, 2017) and that anticipate its moral consequences (Van-den-Hoven, 2013). Therefore, although some authors equate RRI with CSR, we believe that RRI has a broader scope that affects the entire structure of organisations. The application of RRI to an institution cannot be limited to the restricted field of its CSR. Other authors, experts in RRI, have expressed similar views (Ribeiro; Smith; Millar, 2017; Von-Schomberg, 2013).

Although there is increasing interest in RRI within corporate environments, there are very few examples of its implementation in organisations. Many companies do not know this concept, developed in an academic environment, or consider that the narrative of RRI is not appropriate to their reality, while others carry out ini-
Although some authors equate RRI with CSR, we believe that RRI has a broader scope that affects the entire structure of organisations 
tiatives similar to RRI, related, for example, with sustainable innovation, participative design, open innovation, dialogue with interested parties, the development of scenarios, the circular economy, etc. Therefore, an integral vision is required in which RRI connects with business strategy and Corporate Social Responsibility (Van-de-Poel et al., 2017).

Van-de-Poel et al. (2017) propose a model to adapt RRI to the business world, taking into account the distinction between the strategic and the operational dimensions of RRI, and so avoiding the creation of activities that do not arise out of an authentic strategy. For this purpose, they conceived the use of key performance indicators (RRI KPIs). On the other hand, Gurzawska, Mäkinen, and Brey (2017) maintain that businesses that do not adopt RRI risk losing competitive opportunities and facing negative impacts on financial, societal and environmental levels.

One of the main sources of discord when extrapolating this discipline outside the research setting is that social and ethical aspects have to be addressed by deliberative engagement with stakeholders throughout the process, which in the case of corporate communications implies an authentic change in power structures. Brand and Blok (2019) have already discussed the difficulty of establishing the extent to which empowerment of the whole of society can be adopted in corporations, due to the tensions that arise in the business world when RRI is applied, as it can affect innovative capacity, competitive advantages and corporate governance structures.

In the context of an organisation's ethics, a public commitment to transparency and participation is necessary, and this requires

"organisational processes and structures that permit and strengthen responsible communication" and that allow "openness and access to information, and the possibility of engagement" for all groups of stakeholders (García-Marzá, 2017, p. 271).

Brand and Blok (2019) define deliberative engagement in RRI as

"the reflective communication of innovators and researchers with stakeholders and the wider public about the social and ethical aspects of innovation (processes)",

so generating a change in the power structures and in decision-taking. The authors review the debate so far on the theory of stakeholders, including the dilemma of who counts as a legitimate stakeholder. Their conclusion is that this theory places much emphasis on stakeholder commitment and the dialogue, linking this to the emphasis of RRI on deliberative engagement. However, to adapt RRI to the business world, we must go further, and extend the innovation process to an even wider group of actors: the general public.

For Brand and Blok (2019), the application of RRI to the business world requires readjusting the balance between processes and results, since the current academic publications on the subject are focussed more on the procedural requisites. The authors encourage workers in the field of RRI to consider the tensions mentioned above when applying the discipline to a commercial environment, in order to be more pragmatic and less idealistic. These modifications should also be applied to the ideal of commitment and deliberative engagement, using less severe standards of transparency and inclusiveness in commercial innovation. Participation in RRI in business would rather be an instrumental procedure for achieving the primary aim of RRI: the consideration of ethical and social values.

Although the application of RRI in a business context is still recent, Brand and Blok (2019) provide a collection of studies linking RRI to Corporate Social Responsibility. In this line, latridis and Schroeder (2016) show that the tools of corporate responsibility can be used to achieve responsible innovation in businesses, and Voegtlin and Scherer (2017) argue that RRI in businesses could be especially relevant for multinational companies. Other studies delve into the motivations that companies may have to incorporate responsible innovation (Garst et al., 2017) and even compare RRI with social and sustainable entrepreneurship (Lubberink et al., 2017) and open innovation (Long; Blok, 2018).

The main work along these lines is that of Gurzawska, Mäkinen, and Brey (2017), who offered a comparison between the concepts of RRI and CSR, since both are centred on corporate responsibility and stakeholder engagement. However, these authors insist that RRI represents a top to bottom perspective, created politically to induce the use of these principles in research and innovation, while CSR represents a bottom to top perspective in which policies function as a self-regulatory mechanism so that businesses can ensure compliance with the law, as well as with the spirit of the law and ethical and international standards. For our part, we would extend this aspect of the comparison, in as much as that in RRI, a bottom to top perspective is also required, given that stakeholders and final beneficiaries should participate in the innovation process right from the start.

Gurzawska, Mäkinen, and Brey (2017) provide additional criteria in their study, affirming that RRI is centred on ethical evaluation and social impact, while CSR focusses on the community and the environment (Gauttier et al., 2017). While CSR can generally be applied to all of a company's activities, including research and innovation, it is not specifically designed to affect Research and Development and innovation (R\&D\&i). Finally, Gurzawska, Mäkinen and Brey (2017) concluded that although RRI has to be adapted in order to apply it to the business world, it is currently a viewpoint that can 
provide value to both industry and society, in alignment with the government and the academic world, something that CSR strategies cannot currently achieve. In addition, Porter and Kramer (2006) have established that the debate about CSR is centred on the tension between businesses and society, so companies must feed off their surroundings. Therefore, both CSR and RRI should concentrate on creating shared value, CSV, with societal stakeholders. This comparison between RRI and CSR is also examined by Van-de-Poel et al. (2017), who considered that RRI could merit the same criticisms. For example, if RRI is considered as a new corporate label that is instrumentalised to smooth innovation's path into society, or to achieve previously established policies (Owen; Macnaghten; Stilgoe, 2012). Therefore, as in the case of CSR, the motives behind RRI can influence accountability for actions taken and the results desired and achieved, from simply gaining acceptance to actually incorporating different forms of knowledge obtained from experts and diverse stakeholders.

According to Van-de-Poel et al. (2017), a CSR strategy designed to include aspects of RRI will require companies to go beyond reactive and defensive policies and deal proactively with social, environmental and ethical aspects. This implies actively anticipating the effects that may be caused by their processes, products or services, which groups will be affected, and other aspects such as the environmental footprint. The company should accept responsibility for all this, not simply to avoid damaging society, but rather, to offer a benefit. In this way, RRI can help businesses to achieve the so-called triple bottom line, of social, financial and environmental full-cost accounting, right from the start of their processes (Pavie; Scholten; Carthy, 2014).

García-Marzá (2017) alerts us to the breach between the Corporate Social Responsibility strategy and its communication. Among the public, a lack of confidence and credibility is extending with respect to the impacts produced by integrating social, financial and environmental benefits with corporate profits. Sometimes, social responsibility is seen as a merely cosmetic, even superficial aspect, as an instrument that allows "covering up bad administrative practices" or even "hindering the passage of necessary legislation".

Finally, as indicated by Van-de-Poel et al. (2017), RRI can become a factor in the equation to resolve the dilemma of the balance between predictability and the costs of change, since the aim of an RRI strategy is early identification of the potential social effects of the process of innovation, while the aim of CSR is to ensure that a company's operations are governed by ethical principles and take into account the interests and needs of legitimate stakeholders. According to many authors (Flipse et al., 2015; Lees; Lees, 2018; Nathan, 2015; Scholten; Duin, 2015; Van-de-Poel et al., 2017), RRI is more proactive than CSR and provides clear competitive advantages, such as:

- greater knowledge about clients and stakeholders;

- identification of latent needs that may generate new business opportunities;

- improving social acceptability and mitigating scenarios in which the company would meet with social criticism;

- constructing a relationship of trust with society;

- demonstrating to governments that, as businesses, they take their responsibilities seriously, and so can assume voluntary agreements instead of being bound by external regulations.

The use of this discipline, RRI, can improve the CSR strategy and its communication, since it is a philosophy of renovation, encrusted in the very governance and structure of the company and so forming part of the corporate identity. In this way, RRI frames all business activity, from the R\&D\&i process through to production, marketing and communication of the product or service.

In this investigation, our aim is to contrast the concept of RRI as found in international publications with the opinions of Spanish experts who have practical experience of the application of RRI. The objective of this study is to demonstrate the possibilities for applying the principles of this new discipline of RRI to the business world and to corporate communications, and to identify the main barriers and benefits involved in its adoption.

\section{Methodology}

To achieve the foregoing objectives, we have carried out an exhaustive documentary review that we offer as a contribution to the scientific debate, and an analysis of fifteen semi-structured interviews with experts in different areas. This qualitative approach to the subject of the study, the application of RRI to the business world and to corporate communications, allows us to obtain a type of information regarding the how and the why that could not be achieved with a more quantitative approach (Aceituno-Aceituno et al., 2018).

The study is part of the project Fostering a Transition towards Responsible Research and Innovation Systems (FoTRRIS), financed by the European Commission, that introduced new practices in governance to promote (co-)RRI. The addition of the "co-" prefix emphasises that this discipline is a collaborative activity right from the start of the process.

The most relevant challenges for society at this moment are global in nature, but they produce local effects. For this reason, the project focussed on "glocal" phenomena; that is, on regional manifestations of global challenges, and local 
opportunities for resolving them. In this framework, experiments were carried out to examine governance from local (co)RRI competence cells in which representatives from the academic world and from administrations, industry and society in general were included. These four groups of stakeholders form the so-called quadruple helix of RRI and, as this discipline demands, all participated in the co-design, co-development and co-evaluation of all of the innovation processes in FoTRRIS (2018).

We move in a global social context in which networks of relationships pay no regard to international frontiers, creating interdependence between local, national, regional and supranational subjects. There are no places, nor social groups, exempt from this, so common values and standards are necessary (García-Marzá, 2018). This situation, characterised by the global nature of many problems that must be faced by corporations, and even small businesses, underlines the importance of corporate codes of ethics. There is little that national legislation or tradition can do in the face of these global, multicultural challenges. Codes of ethics provide

"values, commitments and conduct assumed by the organisation, where ever it operates, demonstrating a character (...) in accordance with the moral values expressed in international directives and agreements, such as the Global compact or the Sustainable development goals" (García-Marzá, 2017).

There is a point to be made here, that in this process of global communication, the different participants continue to think as locals (Castells, 2008). For this reason, it is relevant to focus on "glocal" phenomena; that is, on regional manifestations of these global challenges and on local opportunities for resolving them (FoTRRIS, 2018).

In view of the above, it is especially relevant to carry out this Spanish study with the participation of 15 experts from different areas who were selected because they were pioneers in the application of RRI techniques and principles in asyet scarce pilot projects in Spain. These interviews with experts from the different helices took place during the entire process of data collection and project analysis, from March 2016 to March 2018.

In the 15 semi-structured interviews, some face to face, some via video conference, the intention was to discover the opinions of relevant experts from the quadruple helix (education and research, business and industry, policy makers and civil society) in respect to certain key points. The script of the interviews included the following questions:

- A brief description of the professional context of the interviewee.

- What are the main drivers of innovation?

- Do you believe that the new governance practices are applicable to innovation?

- What are the main characteristics of RRI?

- Are more responsible innovation and communications necessary?

- What is your opinion regarding (co)RRI?

- Do you know of mechanisms or processes that include RRI principles?

- To what extent do existing mechanisms, processes and activities represent a base on which to establish (co)RRI?

- How could RRI become an institutionalised practice in the private sector, and not solely in the public sector? The responses to these questions will guide the analysis in the following section.

\section{Summary and discussion of the results}

Table 1. Profile of interviewees

\begin{tabular}{|l|l|l|l|}
\cline { 2 - 4 } \multicolumn{1}{l|}{} & \multicolumn{1}{|c|}{ Sex } & \multicolumn{1}{c|}{ RRI Sector } & \multicolumn{1}{c|}{ Profile } \\
\hline E1 & Male & Business sector & Accessible tourism for persons with functional diversity. \\
\hline E2 & Male & Academia & Professor and Researcher in Computer Engineering. President of scientific association. \\
\hline E3 & Male & Academia & Professor and Researcher in Economics and Mathematics. \\
\hline E5 & Woman & Academia & Professor and Researcher in Communication and Accessible Culture. \\
\hline E6 & Woman & Society in general & Researcher with expertise in RRI and citizen participation. \\
\hline E7 & Woman & Society in general & Social worker with expertise in persons with functional diversity. \\
\hline E8 & Male & Academia & $\begin{array}{l}\text { Researcher with functional diversity expert in accessibility. Experience in Marketing and } \\
\text { Communications. }\end{array}$ \\
\hline E9 & Male & Academia & Professor and Researcher in RRI applied to technology. \\
\hline E10 & Woman & Academia & Researcher with expertise in technology and accessibility. Faculty Director. \\
\hline E11 & Male & $\begin{array}{l}\text { Society in general/ Business } \\
\text { sector }\end{array}$ & Psychotherapist in NPO, coordinator of health and education programs. \\
\hline E12 & Woman & $\begin{array}{l}\text { Society in general/ Business } \\
\text { sector }\end{array}$ & Journalist and Paralympic athlete. Women's association. \\
\hline E13 & Male & Academia & Professor and Researcher in the Philosophy of Science. Faculty Director. \\
\hline E14 & Woman & Policy makers. & Project director of regional rectors' conference. \\
\hline E15 & Male & Policy makers. & Local government in Spain. \\
\hline & & & \\
\hline
\end{tabular}


Several interviewees with an academic profile come from universities and research centres, while others are from non-profit organisations. Others have experience with disabled persons, since the study of the competence cell concentrated on women with functional diversity. Most of the interviewees were involved in some type of research activity, even when this was not their main work.

The uneven distribution of the sample is due to the difficulty in finding persons involved in RRI initiatives from the business and political/administrative sectors. This is despite the general conclusion that can be drawn from the review of the literature, which is that RRI could provide significant benefits in the business world and in corporate communications, although certain barriers must be overcome.

For example, most of the interviewees though that what drives innovation is paying attention to social actors in all of their diversity, whether they be direct beneficiaries or another type of social group. Reaching the maximum number of beneficiaries would also improve the public's evaluation of science. In addition, E4 asserted that financial benefits are also obtained with social objectives. E6 complained that at times, there does not appear to be a genuine desire to change things

Except for E10, all of the interviewees agreed that participative governance is important for innovation. Such active listening may require investing more time and work in debate, but we can learn a lot from social movements. On the other hand, many thought that a true democracy does not exist, because there is no real equality of opportunities as regards accessibility. According to E13, it is necessary to find a new, radical concept of governance practices based on co-responsibility.

With respect to the main characteristics of RRI, the interviewees indicated listening, cooperation and debate with the different social actors throughout the entire process. Being collaborative and reflexive allows practical results with social impact to be defined from the start, improves accessibility and extends the number of possible beneficiaries. For them, $\mathrm{RRI}$ is anticipatory. It changes both the results and the research process and it implies a process of continuous evolution and improvement, giving rise to more transversal and multidisciplinary innovation. They feel that technology helps through interaction and interactivity, but that human relationships and practicality are also necessary. The collaboration between stakeholders favours transparency, since the social actors supervise the project. The interviewees mention and describe the dimensions of RRI reported by Stilgoe, Owen and Macnaghten (2013).

The interviewees coincided in the necessity for more responsible innovation and communications in the present context, following the economic crisis, since the general public is aware of corruption and egoism, and of the crisis of values, of the increase in social inequality and of increasing contamination. All of this has created a civilisation that demands greater sustainability. Researchers and innovators should work on these great challenges. As already noted by the sectors most critical of CSR, the interviewees affirmed that more equal and human values need to be fomented to achieve greater social impact. When resources are scarce, agents should be more responsible and transparent. There are sectors in society that want to be heard, such as social movements. However, this change in the structures of power may discourage leaders in the academic, financial and social sectors (E13).

The specific vision of (co)RRI is that it is seen as a driving force for social and environmental development and improvement, but also as a driver of the economy, since it can contribute results that are actually applicable, with a great social impact. Doubts arise as to the real applicability of RRI outside academia: whether (co)RRI can influence the real state of affairs, and whether it can succeed promoting changes to standards. Concerning such a change, the interviewees mentioned different barriers, such as the lack of finance, excessive bureaucracy, and lack of interest on the part of public and private leaders. It is evident that for RRI to be adopted in the business world and in corporate communications, changes are needed in the very concept of RRI (Brand; Blok, 2019).

Everyone coincides in that they know of methods or processes that include RRI principles, even though they are not explicitly recognised as such. This phenomenon is also found in the corporate world, as already noted by Van-de-Poel et al. (2017). To analyse this item, we have focussed on initiatives produced outside the academic environment:

- E7 underlines the existence of "interesting projects that have changed the social intervention system", like those related to homeless persons with functional diversity and distance learning for persons with functional diversity. These activities enjoyed support from businesses that allowed these groups to be incorporated into the labour force and promoted entrepreneurship.

- E8, apart from being a researcher, works in guaranteeing technological access for a banking institution.

- E11 believes that the (co)RRI perspective represents the future, since collaboration with the different sectors and active listening to the final beneficiaries is essential. This interviewee works in an NPO located in Uganda, creating prostheses and other tools using 3D printing. To this end, his organisation collaborates with a Spanish technological company. All is free, and they are even preparing a web site for "free global access without restrictions" where anyone interested can obtain their designs. This initiative also counts on the support of the local population ("you can't arrive anywhere with a very clear idea and not allow people to get involved") and public institutions like hospitals and universities. 
- E12 is contacting many social entrepreneurs, and these energisers are demonstrating that this collaborative system works, that this business model can generate profits and at the same time help others. For example, she has climbed Kilimanjaro in a wheelchair to create an adaptable technology for people who genuinely need it, and she has also created a platform to favour access to distant places.

- The town hall where E15 works participates in 16 European projects on intelligent cities, and is a point of reference in this field. In them, they follow the basic philosophy of guaranteeing that the information is accessible and reaches all interested parties.

- E6 indicates that, for these experiments to work, it is essential that, on a personal level, each individual remain faithful to the objectives of RRI.

- E4 comments that these experiments work, but that there are no "ideal models".

The interviewees were asked to what extent existing mechanisms, processes and activities represent a base on which to establish (co)RRI. The answers varied, from seeing them as inspirational practices with a view to the future of RRI, contributions of new perspectives, methods or planning systems, right on up to more specific considerations applied to business communications.

- E8 said that in the banking institution where he works, initiatives of this type that could be seen as related to (co)RRI, are not undertaken because the organisation is obliged to do so, but because they form a part of their strategic sustainability strategy, and if this can happen in this bank it could also happen in many other companies.

- E5 defined the current situation as inspirational practices, "since perfect RRI does not exist".

Finally, we reach the most relevant question in terms of the objectives of this article: How could RRI become an institutionalised practice in the private sector, and not solely in the public sector? The interviewees coincide in that the implication and awareness of all social agents are needed, as is an authentic collaboration between the different public and private areas. Some of them commented that more resources must be invested in this.

- E12 maintained a critical attitude towards public management, which would allow for the institutionalisation of (co) RRI. One of the interviewees indicated that it would be essential to count on the implication of the persons affected by innovation and to consult them when developing practices of this type.

- E2 mentioned that economic incentives are needed for private companies, and evaluations of quality for public bodies, in order to apply these practices properly.

- E11 feels that the push must come from the public sector, since private companies cannot be obliged to apply (co)RRI. In consequence, it must be a voluntary practice in the private sector, bearing in mind the importance of CSR in the business world

- E10 mentioned the need to integrate academic initiatives into the private sector, and that this requires

"willingness, and adapting their way of life (...) Closeness between universities and businesses seems beneficial to me, and I believe that this type of collaboration should be encouraged. But it also leads to difficulties, because the rhythms and objectives are very different".

- This practical character of businesses is a definite incentive to adapt (co)RRI (E12).

- For E8, "it would be very useful if [(co)RRI] were institutionalised".

"For businesses, it increases competitiveness and it helps their reputation, and for the academic world, it increases funding for more and better research. In the end, everybody benefits".

- In E7's words, it would be beneficial, but complicated

"because society itself must be held responsible (...) people must be able to demand this responsible innovation or investigation from society and the powers that represent it".

- E6 goes further than this, and says that human beings, in all their diversity, must be considered of overriding importance. For this interviewee,

"A change in ethical, legislative or regulatory codes is not enough, although it would be a good start".

- E3 contributes instructions for a model for institutionalisation, consisting of

"offering participation from the start to the business world, to social agents, to potential users, etc., forming a committee charged with approving the innovation".

\section{Conclusions}

Responsible Research and Innovation (RRI) implies that social stakeholders representing the quadruple helix (academia, policy makers, business, and society in general) should work together during the entire innovation process in order to improve the fit of the results with the values, needs and expectations of society.

In this study, we have achieved the defined objective, since, via an exhaustive review of the literature and an analysis of 15 interviews with experts representing the quadruple helix, we have obtained evidence relative to the benefits and the barriers associated with the application of the principles of the emerging discipline of RRI in the business world and in corporate communications.

The implication of all social agents is necessary, as is a real collaboration between the public and private sectors 
The experts we interviewed stress the urgency of applying the quadruple helix, in order to create participative structures that can help companies to achieve a more socially and environmentally sustainable activity. To generate this change, it is necessary that the philosophy of RRI impregnates the forms of business governance, although the experts insist that one of the main barriers to the application of RRI resides in the cost of change, not simply from a financial viewpoint, but also in terms of business mentality.

In this way, according to the interviewees and the academic literature, the application of the four principles of RRI defined by Stilgoe, Owen y Macnaghten (2013) -anticipation, reflexivity, inclusiveness and responsiveness- to corporate communications would contribute to competitive advantages, with products and services genuinely accepted and desired by society.

The interviewees stressed the importance of participative governance in organisations, but the review of the literature shows the difficulties that this may mean in the business world, and in particular, in corporate communications. As a result, as indicated by one interviewee, co-responsibility could be of special relevance in this regard. Additionally, it would be necessary to adapt RRI to be less demanding than the form applied in the academic world, so that it could subsequently be adapted for other organisations, as defended by Brand and Blok (2019).

Currently, there is a scientific debate, mentioned in this article, in which some authors suggest that RRI implanted in the business world would be similar to CSR. However, our position coincides with that of other RRI experts (Ribeiro; Smith; Millar, 2017; Von-Schomberg, 2013), who see this emerging discipline as a global perspective that affects all structures and processes in organisations. This would mean that RRI implies a movement that integrates all of a company's activities, governance practices, innovation and research processes, etc., including other current initiatives that go by different names, such as sustainable innovation, participative design, open design, dialogue with groups of interest or circular economy, among others.

We find ourselves, therefore, facing a social demand to which the business world should provide a response, and RRI is a possible solution, since it considers social, environmental and ethical aspects from a collaborative and responsible approach, that also seeks to align itself with the real values, needs and expectations of societies.

\section{References}

Aceituno-Aceituno, Pedro; Casero-Ripollés, Andreu; Escudero-Garzás, José-Joaquín; Bousoño-Calzón, Carlos (2018). "Formación universitaria sobre el emprendimiento en proyectos empresariales de comunicación y periodismo". Comunicar, v. 26, n. 57, pp. 91-99.

https://doi.org/10.3916/C57-2018-09

Brand, Teunis; Blok, Vincent (2019). “Responsible innovation in business: A critical reflection on deliberative engagement as a central governance mechanism". Journal of responsible innovation, v. 6, n. 1, pp. 4-24.

https://doi.org/10.1080/23299460.2019.1575681

Castells, Manuel (2008). “Communication, power and counterpower in the network society (II)”. Telos, v. 75, pp. 11-23. https://pimentalab.milharal.org/files/2012/11/Manuel-Castells-Comunicacion-Poder-y-Contrapoder-parte2.pdf https://telos.fundaciontelefonica.com/archivo/numero075/communication-power-and-counterpower-in-the-networksociety-ii

European Union (2014). Rome declaration on responsible research and innovation in Europe. Brussels: European Union. https://ec.europa.eu/research/swafs/pdf/rome_declaration_RRI_final_21_November.pdf

Flipse, Steven M.; Van-Dam, Koen H.; Stragier, Jeroen; Oude-Vrielink, Joric C.; Van-der-Sanden, Maarten C. A. (2015). "Operationalizing responsible research and innovation in industry through decision support in innovation practice". Journal on chain and network science, v. 15, pp. 135-146.

https://doi.org/10.3920/JCNS2015.x004

FoTRRIS (2018). Fostering a transition towards responsible research and innovation systems. http://fotrris-h2020.eu

García-Marzá, Domingo (2017). “From ethical codes to ethical auditing: An ethical infrastructure for social responsibility communication". El profesional de la información, v. 26, n. 2, pp. 268-276.

https://doi.org/10.3145/epi.2017.mar.13

García-Marzá, Domingo (2018). "Sociedad civil global: hacia una ética de las instituciones". Filosofia. Revista da Faculdade de Letras da Universidade do Porto, v. 34, pp. 31-44.

https://doi.org/10.21747/21836892/fil34a2

Garst, Jilde; Blok, Vincent; Jansen, Léon; Omta, Onno S. W. F. (2017). “Responsibility versus profit: The motives of food firms for healthy product innovation". Sustainability, v. 9, n. 12, pp. 1-29.

https://doi.org/10.3390/su9122286 
Gauttier, Stephanie; Søraker, Johnny-Hartz; Brey, Philip; Mäkinen, Markus (2017). Models of RRI in industry. Deliverable 3.3. Responsible industry project.

https://bit.ly/2yEQIoF

Giraldo-Dávila, Andrés-Felipe; Maya-Franco, Claudia-María (2016). “Modelos de ecología de la comunicación: análisis del ecosistema comunicativo". Palabra clave, v. 19, n. 3, pp. 746-768.

https://doi.org/10.5294/pacla.2016.19.3.4

Gurzawska, Agata; Mäkinen, Markus; Brey, Philip (2017). “Implementation of responsible research and innovation (RRI) practices in industry: Providing the right incentives". Sustainability, v. 9, n. 10, pp. 1759.

https://doi.org/10.3390/su9101759

latridis, Konstantinos; Schroeder, Doris (2016). Responsible research and innovation in industry. The case for corporate responsibility tools. Cham: Springer International Publishing. ISBN: 9783319216935 https://doi.org/10.1007/978-3-319-21693-5

Lees, Nic; Lees, Isobel (2018). “Competitive advantage through responsible innovation in the New Zealand sheep dairy industry". International food and agribusiness management review, v. 21, n. 4, pp. 505-524.

https://doi.org/10.22434/IFAMR2017.0013

Long, Thomas B.; Blok, Vincent (2018). "Integrating the management of socio-ethical factors into industry innovation: Towards a concept of open innovation 2.0". International food and agribusiness management review, v. 21, n. 4, pp. 463-486.

https://doi.org/10.22434/IFAMR2017.0040

Lubberink, Rob; Blok, Vincent; Van-Ophem, Johan; Omta, Onno S. W. F. (2017). "Lessons for responsible innovation in the business context: A systematic literature review of responsible, social and sustainable innovation practices". Sustainability, v. 9, n. 5, p. 721.

https://doi.org/10.3390/su9050721

Nathan, Ganesh (2015). "Innovation process and ethics in technology: An approach to ethical (responsible) innovation governance". Journal on chain and network science, v. 15, n. 2, pp. 119-134.

https://doi.org/10.3920/JCNS2014.x018

Owen, Richard; Macnaghten, Phil; Stilgoe, Jack (2012). "Responsible research and innovation: From science in society to science for society, with society". Science and public policy, v. 39, n. 6, pp. 751-760.

https://doi.org/10.1093/scipol/scs093

Pavie, Xavier; Scholten, Victor; Carthy, Daphné (2014). Responsible innovation: from concept to practice. Singapur: World Scientific. ISBN: 9789814525077

Porter, Michael E.; Kramer, Mark R. (2006). "Strategy and society: The link between competitive advantage and corporate social responsibility". Harvard business review, v. 84, n. 12, pp. 78-92.

https://www.comfama.com/contenidos/servicios/Gerenciasocial/html/Cursos/Columbia/Lecturas/Strategy-Society.pdf

Ribeiro, Barbara E.; Smith, Robert D. J.; Millar, Kate (2017). “A mobilising concept? Unpacking academic representations of responsible research and innovation". Science and engineering ethics, v. 23, n. 1, pp. 81-103.

https://doi.org/10.1007/s11948-016-9761-6

Scholten, Victor; Van-der-Duin, Patrick A. (2015). "Responsible innovation among academic spin-offs: How responsible practices help developing absorptive capacity". Journal on chain and network science, v. 15, n. 2, pp. 165-179.

https://doi.org/10.3920/JCNS2015.x005

Stilgoe, Jack; Owen, Richard; Macnaghten, Phil (2013). “Developing a framework for responsible innovation”. Research policy, v. 42, n. 9, pp. 1568-1580.

https://doi.org/10.1016/j.respol.2013.05.008

Van-de-Poel, Ibo; Asveld, Lotte; Flipse, Steven; Klaassen, Pim; Scholten, Victor; Yaghmaei, Emad (2017). “Company strategies for responsible research and innovation (RRI): A conceptual model". Sustainability, v. 9, n. 11, p. 2045. https://doi.org/10.3390/su9112045

Van-den-Hoven, Jeroen (2013). "Value sensitive design and responsible innovation". In: Owen, Richard; Bessant, John; Heintz, Maggy. Responsible innovation. Chichester: John Wiley \& Sons, pp. 75-83. ISBN: 9781119966357 https://doi.org/10.1002/9781118551424.ch4

Voegtlin, Christian; Scherer, Andreas-Georg (2017). "Responsible innovation and the innovation of responsibility: Governing sustainable development in a globalized world". Journal of business ethics, v. 143, n. 2, pp. 227-243.

https://doi.org/10.1007/s10551-015-2769-z

Von-Schomberg, René (2013). "A vision of responsible research and innovation". In: Owen, Richard; Bessant, John; Heintz, Maggy. Responsible innovation. Chichester: John Wiley \& Sons, pp. 51-74. ISBN: 9781119966357

https://doi.org/10.1002/9781118551424.ch3 